\title{
Definitions and Assessment Approaches for Emergency Medical Services for Children
}

Susan Fuchs, MD, ${ }^{a}$ Mark Terry, NRP, MPA, ${ }^{b}$ Kathleen Adelgais, MD, MPH, ${ }^{c}$ Marlene Bokholdt, MS, RN, CPEN, ${ }^{d}$

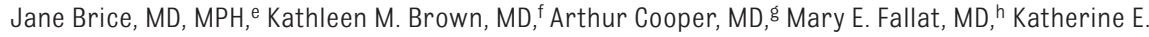
Remick, MD, ${ }^{i}$ Keith Widmeier, BA, NRP, CCEMT-P, ${ }^{j}$ Wendy Simon, MA, CAE, ${ }^{k}$ Melissa Marx, BA ${ }^{k}$

Pediatric Life Support (PLS) courses and instructional programs are educational tools developed to teach resuscitation and stabilization of children who are critically ill or injured. A number of PLS courses have been developed by national professional organizations for different health care providers (eg, pediatricians, emergency physicians, other physicians, prehospital professionals, pediatric and emergency advanced practice nurses, physician assistants). PLS courses and programs have attempted to clarify and standardize assessment and treatment approaches for clinical practice in emergency, trauma, and critical care. Although the effectiveness of PLS education has not yet been scientifically validated, the courses and programs have significantly expanded pediatric resuscitation training throughout the United States and internationally. Variability in terminology and in assessment components used in education and training among PLS courses has the potential to create confusion among target groups and in how experts train educators and learners to teach and practice pediatric emergency, trauma, and critical care. It is critical that all educators use standard terminology and patient assessment to address potential or actual conflicts regarding patient evaluation and treatment. This article provides a consensus of several organizations as to the proper order and terminology for pediatric patient assessment. The Supplemental Information provides definitions for terms and nomenclature used in pediatric resuscitation and life support courses.

\section{SCOPE OF CURRENT PROJECT}

In 2014, an Emergency Medical Services for Children Task Force was formed to establish consensus on definitions of key terms and the basic approach to pediatric assessment in Pediatric Life Support (PLS). The goal was to identify differences in terminology and pediatric assessment in the existing educational courses and develop common terminology and assessment components that would create a standard approach to care of the child who is critically ill or injured. In addition, key definitions of commonly used terms would be provided.

Organizations that offer PLS courses were invited to participate and included representatives from the following: American Academy of Pediatrics, Emergency Cardiovascular Care Committee of the American Heart Association, National Association of EMS Physicians, Emergency Nurses Association, National Association of Emergency Medical Technicians, Emergency Medical Services for

\section{abstract}

\author{
.
}


TABLE 1 Approach to Assessment by Program Common Elements

\begin{tabular}{|c|c|c|c|c|c|c|c|}
\hline Organization & Course & Audience & ABCDE & PAT & SAMPLE & Physical Exam & Scene Safety \\
\hline \multirow[t]{2}{*}{$\begin{array}{l}\text { American Academy of } \\
\text { Pediatrics }\end{array}$} & $\begin{array}{l}\text { Pediatric Education } \\
\text { for Prehospital } \\
\text { Professionals (PEPP) }\end{array}$ & $\begin{array}{l}\text { Prehospital professionals } \\
\text { (emergency medical } \\
\text { responders, emergency } \\
\text { medical technicians, } \\
\text { paramedics) }\end{array}$ & $X$ & $x$ & $X$ & $X$ & $X$ \\
\hline & $\begin{array}{l}\text { Advanced Pediatric Life } \\
\text { Support (APLS) }\end{array}$ & $\begin{array}{l}\text { Physicians, nurses, pediatric } \\
\text { nurse practitioners } \\
\text { (PNPs), physician } \\
\text { assistants (PAs) }\end{array}$ & $x$ & $x$ & $x$ & $x$ & \\
\hline \multirow{2}{*}{$\begin{array}{l}\text { National Association of } \\
\text { Emergency Medical } \\
\text { Technicians }\end{array}$} & $\begin{array}{l}\text { Prehospital Trauma Life } \\
\text { Support (PHTLS) }\end{array}$ & Prehospital professionals & $x$ & & $X$ & $X$ & $x$ \\
\hline & $\begin{array}{l}\text { Emergency Pediatric } \\
\text { Care (EPC) }\end{array}$ & Prehospital professionals & $X$ & $X$ & $X$ & $X$ & $x$ \\
\hline $\begin{array}{c}\text { American Heart } \\
\text { Association }\end{array}$ & $\begin{array}{l}\text { Pediatric Advanced Life } \\
\text { Support (PALS) }\end{array}$ & $\begin{array}{l}\text { Health care professionals } \\
\text { who respond to } \\
\text { emergencies in infants } \\
\text { and children }\end{array}$ & $x$ & & $x$ & $x$ & \\
\hline $\begin{array}{l}\text { American College of } \\
\text { Surgeons }\end{array}$ & $\begin{array}{l}\text { Advanced Trauma Life } \\
\text { Support (ATLS) }\end{array}$ & $\begin{array}{l}\text { Physicians, nurses, PNPs, } \\
\text { PAs }\end{array}$ & $X$ & & $X$ & $X$ & \\
\hline $\begin{array}{l}\text { Emergency Nurses } \\
\text { Association }\end{array}$ & $\begin{array}{l}\text { Emergency Nursing } \\
\text { Pediatric Course } \\
\text { (ENPC) }\end{array}$ & Emergency nurses & $x$ & $x$ & $x$ & $x$ & \\
\hline $\begin{array}{l}\text { International Trauma Life } \\
\text { Support }\end{array}$ & $\begin{array}{l}\text { International Trauma } \\
\text { Life Support (ITLS) }\end{array}$ & $\begin{array}{l}\text { Prehospital professionals, } \\
\text { physicians, nurses, PNPS, } \\
\text { PAs }\end{array}$ & $x$ & & $x$ & $x$ & $x$ \\
\hline $\begin{array}{l}\text { National Highway Traffic } \\
\text { Safety Administration }\end{array}$ & $\begin{array}{l}\text { EMS education } \\
\text { standards }\end{array}$ & Prehospital professionals & $x$ & & $X$ & $X$ & $X$ \\
\hline
\end{tabular}

$\mathrm{X}$ indicates inclusion in the current curriculum. EMS, Emergency Medical Services for Children; SAMPLE, signs and symptoms, allergies, medications, past history, last meal or liquids, events leading to presentation.

Children National Resource Center, Committee on Trauma on behalf of the American College of Surgeons, American College of Emergency Physicians, and the National Association of EMS Educators.

The task force conducted a series of teleconferences to review existing terminology used in PLS courses. A literature review was conducted to assess scientific support for terminology and teaching models. The task force then met to draft a consensus position on common terminology, which was endorsed by the respective organizations.

\section{PEDIATRIC ASSESSMENT}

Although there are significant similarities in approaches, there is no nationally agreed-on sequence of steps for pediatric emergency assessment. The task force started with an assessment of how each course approaches primary assessment, looking for common elements (see Table 1).

Table 1 lists current courses, including their organizational affiliation and similarities and differences in approaches to assessment.

To improve communication and training, the task force agreed on a consistent approach to patient assessment for all PLS courses and programs. The approach should be taught to all health care providers at all levels and offer consistency in terms, steps in progression, and significance of physical findings. ${ }^{1}$

All courses describe initial assessment of the general appearance of the patient, but differences in terminology were present among courses. The task force chose the Pediatric Assessment Triangle (PAT) ${ }^{1}$ (Fig 1) because it appears to be easy to teach and learn, reproducible

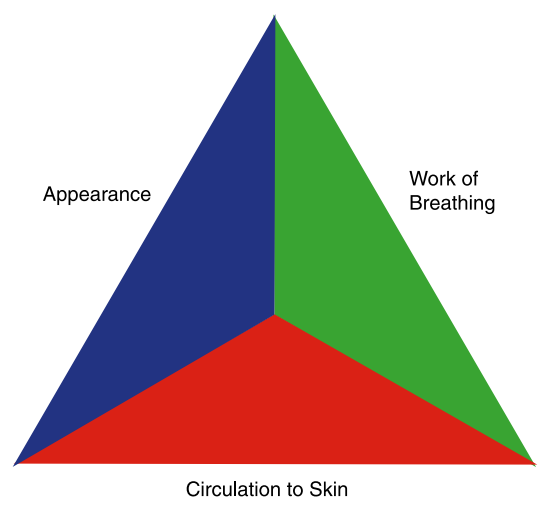

FIGURE 1

PAT. From American Academy of Pediatrics. Pediatric Education for Prehospital Profes sionals. Sudbury, MA: Jones \& Bartlett Publishers; 2000

among all medical provider groups, and medically sound.

The task force suggests the following step-by-step components of the pediatric emergency assessment:

- "Scene safety" is an assessment of safety threats to the prehospital 
care provider, patient, caregiver, and/or bystanders that may differ significantly depending on the environment of practice. Aspects of scene safety may include prevention of exposure to infectious disease and protection from violence or other environmental hazards. ${ }^{2}$ Prehospital professionals routinely develop more sophisticated on-scene safety assessment skills because of their practice environment. Hospital-based health care providers have been exposed to security threats that suggest the need to do the same, and most children's hospitals and units require enhanced security measures for health care providers, ancillary staff, and visitors. The task force chose to focus on common elements of patient assessment rather than operational components of the overall management of the emergency scene.

- The PAT is an observational tool used to make a "general impression," which uses a visual and auditory approach composed of noting the child's general appearance, work of breathing, and circulation. ${ }^{1}$ The PAT can be used immediately on entering the scene and helps identify the general type of physiologic problem (ie, respiratory, circulatory, or neurologic) and urgency for treatment and transport. The PAT begins with evaluation of appearance $(\mathrm{A})$ as an indicator of overall physiologic status, including degree of interactivity, muscle tone, and verbal response or cry. The use of the TICLS (tone, interactivity, consolability, look/ gaze, speech/cry) mnemonic can be used as an adjunct. ${ }^{1,3}$ The second component of the PAT is breathing (B), which determines whether a child has increased work of breathing by assessing the patient's position (ie, tripod or sniffing position), work of breathing (ie, retractions), and adventitial breath sounds (eg, stridor, sonorous respirations). ${ }^{1,3}$ The final component of the PAT evaluates the child's overall circulatory status (C) based on general color (eg, pale, mottled, cyanotic).1,3 A child with abnormal PAT findings requires prompt evaluation and management. The findings of the PAT may indicate need for immediate intervention (eg, cardiopulmonary resuscitation for a patient who is apneic and pulseless, tourniquet use for exsanguinating hemorrhage of an extremity).

- "Primary assessment" (primary survey) uses a hands-on ABCDE (airway, breathing, circulation, disability, exposure) approach and includes assessment of the patient's vital signs (including oxygen saturation by pulse oximetry). This hands-on approach is standardized across various courses and is not further detailed in this article, except for disability, which is evaluated in most courses using the AVPU scale (alert, responds to verbal stimuli, responds to painful stimuli, unresponsive), and by looking at the pupils and assessing motor activity (normal and symmetric versus seizure, posturing, flaccidity). Trauma courses use the Glasgow Coma Scale (GCS) score, which is detailed later in this article. Exposure includes exposing and examining the child for other signs of trauma or illness, paying particular attention to the child's face, trunk, and skin, while taking care to avoid hypothermia.

As the health care provider proceeds through each component of the primary assessment, life-threatening abnormalities that are identified should be treated in real time before completing the remainder of the primary assessment (eg, unless the patient is apneic and pulseless or has obvious uncontrolled external extremity hemorrhage). In patients with life-threatening conditions evident in the primary assessment, correction of those conditions takes precedence over establishing baseline vital sign measures such as blood pressure or pulse oximetry. When the primary assessment is completed and after life-threatening problems have been addressed, the health care provider proceeds to the secondary assessment.

- "Secondary assessment" (secondary survey) consists of a focused history and detailed physical examination with ongoing reassessment of physiologic status and response to treatment. It is an essential part of the trauma evaluation.

- "Focused history": The task force suggests SAMPLE (signs and symptoms; allergies; medications; past history; last meal or liquids consumed, including when consumption occurred; events leading to presentation) as a mnemonic to help recall important components of a focused history. ${ }^{1,3}$ Other questions specific to the disorder may be appropriate.

- "Focused examination" refers to an anatomically oriented examination, typically conducted in head-to-toe manner, which is designed to detect occult injury or disease not identified by the primary assessment. The complexity and thoroughness of the focused examination is based on the context of the illness or injury. Frequent or ongoing reassessment is emphasized as a component of the focused examination.

- "Ongoing reassessment" of all patients is essential to evaluate the response to treatment and to track the progression of identified physiologic and 
anatomic problems. This reassessment should be applied in real time as needed based on the child's clinical condition through all phases of assessment. It should not be limited to the last part of the assessment sequence. New problems also may be identified on reassessment. Data from the reassessment will guide ongoing treatment. The elements of ongoing reassessment are as follows:

- the PAT;

- the ABCDE of the primary assessment with repeat vital signs, including pulse oximetry;

- assessment of abnormal anatomic and physiologic findings; and

- review of the effectiveness of treatment interventions, which may then be reviewed by returning to the PAT in a cyclic manner.

In addition to emphasis on the clinical examination, health care providers often use diagnostic tests to identify the etiology and severity of illness and injury. This component of patient evaluation, called the "diagnostic (tertiary) assessment," uses laboratory and other ancillary procedures (eg, radiologic, invasive hemodynamic). Like ongoing reassessment, it may be performed during other phases of assessment, such as primary or secondary. Although most diagnostic assessment is restricted to the emergency department or hospital settings, point-of-care diagnostic assessment is also used in the outof-hospital setting (eg, rapid glucose, end-tidal $\mathrm{CO}_{2}$ ). These diagnostic tests help confirm the physical assessment of the child's physiologic state, such as the presence of respiratory acidosis consistent with respiratory failure and may be used to guide treatment interventions. As technology develops, point-of-care diagnostic assessment may become more accessible and useful in the resuscitation setting.

\section{KEY ISSUES}

\section{Weight and Drug Dosing}

For most therapeutic interventions, the child's age is less relevant to proper treatment than his or her weight. A child's weight should always be expressed in kilograms. The use of a length-based tape to determine weight and drug dosing as well as appropriate equipment sizing is preferable when a child's weight is unknown. Studies have shown that different age-based weight formulas and physician estimates are prone to more errors than the length-based system. ${ }^{4-6}$ The length-based tape or decision-support tool uses the 50th-percentile weight for any measured length, which is appropriate for most resuscitation drugs, even with patients who are obese. ${ }^{7}$ The use of checklists, dose guides, or software tools to determine drug dosing (usually converts $\mathrm{mg} / \mathrm{kg}$ to $\mathrm{mL}$ of drug needed) after a weight is established is also suggested.

An additional problem with pediatric drug dosing is the weight ceiling for reaching "adult" standard or maximum doses. Although exact weight-based dosing is recommended in children, standard fixed doses are commonly used in adults. To avoid excessive dosing in children who are overweight, the weight provided on the length-based tape should not be adjusted higher based on presumed increased body mass. $^{7}$

\section{Age Definitions}

There are several reasons for trying to define age groups, including consideration of developmental milestones, directing treatment/ triage or transport, and putting patient problems into the relevant context of the pediatric epidemiology of illness and injury. Hence, numerous age definitions appear in PLS policies, procedures, and protocols. Age is also historically used to direct many therapeutic interventions, including infant, child, and adult Basic Life Support and Advanced Life Support interventions. However, a universal definition of the age of a pediatric patient has remained elusive, and this probably will not change in the near future.

The task force believes that interventions should be based on the anatomic and physiologic needs of the individual patient. Age definitions may be reasonable for ease of training and protocol development but should not distract from the need to assess the individual patient. Borderline and anomalous presentations are unavoidable.

The Task Force also suggests common models for categorizing shock and respiratory distress and common definitions for key terms. Refer to the Supplemental Information to review the Task Force's suggestions on commonly used terms and nomenclature.

\section{ABBREVIATIONS}

ABCDE: airway, breathing, circulation, disability, exposure

GCS: Glasgow Coma Scale

PAT: Pediatric Assessment Triangle

PLS: Pediatric Life Support

SIRS: systemic inflammatory response syndrome

TBI: traumatic brain injury 
FINANCIAL DISCLOSURE: The authors have indicated they have no financial relationships relevant to this article to disclose.

FUNDING: Each organization that participated in the collaboration sponsored the travel of its designated representative, and the American Academy of Pediatrics provided the funding for the meetings and administrative efforts of the collaboration.

POTENTIAL CONFLICT OF INTEREST: The authors have indicated they have no potential conflicts of interest to disclose.

\section{REFERENCES}

1. American Academy of Pediatrics. Pediatric Education for Prehospital Professionals, 1st ed. Sudbury, MA: Jones \& Bartlett Publishers; 2000

2. National Emergency Medical Services Education Standards (D0T HS 811 077A). Washington, DC: US Department of Transportation, National Highway Traffic Safety Administration; 2009

3. American Academy of Pediatrics. Pediatric Education for Prehospital
Professionals. 3rd ed. Burlington, MA: Jones \& Bartlett Learning; 2016

4. Rosenberg M, Greenberger S, Rawal A, Latimer-Pierson J, Thundiyil J. Comparison of Broselow tape measurements versus physician estimations of pediatric weights. Am J Emerg Med. 2011;29(5):482-488

5. So TY, Farrington E, Absher RK. Evaluation of the accuracy of different methods used to estimate weights in the pediatric population. Pediatrics. 2009;123(6).
Available at: www.pediatrics.org/cgi/ content/full/123/6/e1045

6. Hashikawa A, Juhn Y, Homme J, Gardner B, Moore B. Does length-based resuscitation tape accurately place pediatric patients into appropriate color-coded zones? Pediatr Emerg Care. 2007;23(12):856-861

7. Luten R, Zaritsky A. The sophistication of simplicity . . . optimizing emergency dosing. Acad Emerg Med. 2008;15(5):461-465 


\section{Definitions and Assessment Approaches for Emergency Medical Services for}

\section{Children}

Susan Fuchs, Mark Terry, Kathleen Adelgais, Marlene Bokholdt, Jane Brice, Kathleen

M. Brown, Arthur Cooper, Mary E. Fallat, Katherine E. Remick, Keith Widmeier, Wendy Simon and Melissa Marx

Pediatrics 2016;138;

DOI: 10.1542/peds.2016-1073 originally published online November 11, 2016;

\begin{tabular}{|c|c|}
\hline $\begin{array}{l}\text { Updated Information \& } \\
\text { Services }\end{array}$ & $\begin{array}{l}\text { including high resolution figures, can be found at: } \\
\text { http://pediatrics.aappublications.org/content/138/6/e20161073 }\end{array}$ \\
\hline References & $\begin{array}{l}\text { This article cites } 4 \text { articles, } 1 \text { of which you can access for free at: } \\
\text { http://pediatrics.aappublications.org/content/138/6/e20161073\#BIBL }\end{array}$ \\
\hline Subspecialty Collections & $\begin{array}{l}\text { This article, along with others on similar topics, appears in the } \\
\text { following collection(s): } \\
\text { Emergency Medicine } \\
\text { http://www.aappublications.org/cgi/collection/emergency_medicine_ } \\
\text { sub }\end{array}$ \\
\hline Permissions \& Licensing & $\begin{array}{l}\text { Information about reproducing this article in parts (figures, tables) or } \\
\text { in its entirety can be found online at: } \\
\text { http://www.aappublications.org/site/misc/Permissions.xhtml }\end{array}$ \\
\hline Reprints & $\begin{array}{l}\text { Information about ordering reprints can be found online: } \\
\text { http://www.appublications.org/site/misc/reprints.xhtml }\end{array}$ \\
\hline
\end{tabular}




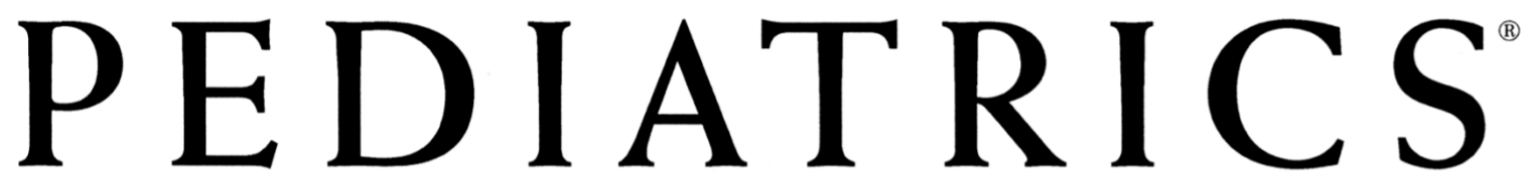

OFFICIAL JOURNAL OF THE AMERICAN ACADEMY OF PEDIATRICS

Definitions and Assessment Approaches for Emergency Medical Services for Children

Susan Fuchs, Mark Terry, Kathleen Adelgais, Marlene Bokholdt, Jane Brice, Kathleen

M. Brown, Arthur Cooper, Mary E. Fallat, Katherine E. Remick, Keith Widmeier,

Wendy Simon and Melissa Marx

Pediatrics 2016;138;

DOI: 10.1542/peds.2016-1073 originally published online November 11, 2016;

The online version of this article, along with updated information and services, is located on the World Wide Web at:

http://pediatrics.aappublications.org/content/138/6/e20161073

Data Supplement at:

http://pediatrics.aappublications.org/content/suppl/2016/11/09/peds.2016-1073.DCSupplemental

Pediatrics is the official journal of the American Academy of Pediatrics. A monthly publication, it has been published continuously since 1948. Pediatrics is owned, published, and trademarked by the American Academy of Pediatrics, 141 Northwest Point Boulevard, Elk Grove Village, Illinois, 60007. Copyright $\odot 2016$ by the American Academy of Pediatrics. All rights reserved. Print ISSN: 1073-0397. 